\title{
Customer Satisfaction: Moderator of e-Business Performance and e-Business Liveability
}

\author{
Fahad Algarni ${ }^{1 *}$, Yen Cheung ${ }^{1}$, Vincent Lee ${ }^{1}$, Azmat Ullah ${ }^{2}$ \\ ${ }^{1}$ Clayton School of Information Technology. Monash University, Melbourne, Australia. \\ 2 La Trobe University, Department of Computer Science and Computer Engineering, Melbourne, Australia. \\ * Corresponding author. Tel.: +61 03 94694602; email: algarni.fahad@monash.edu \\ Manuscript submitted May 10, 2014; accepted August 6, 2014. \\ doi: $10.17706 /$ jsw.10.5.524-537
}

\begin{abstract}
With increased customer power, a way of doing successful and sustainable e-business is to understand users' satisfaction, which drives e-business performance. At the same time, countries are applying liveability and benchmarking indices to make comparisons between cities. While there is no established framework or definition of liveability, a wide range of liveability measures such as political, economic social environment; public services; transportation; housing and consumer goods are used to rank countries/cities in the world in terms of their liveability. Drawing from the literature, we formulated a generic framework that comprises the antecedences of e-business customer satisfaction, which moderates the relationship between e-business performances to e-business liveability. Previous findings suggested that high levels of e-business performance were driven by strong customer satisfaction. Using the generic framework we aim to establish the moderating effect of e-business customer satisfaction on the e-business performance and e-business liveability link. Our initial results show that high e-business customer satisfaction leads indirectly to high e-business liveability. Further work involves testing the framework in other environments to validate the moderation effects.
\end{abstract}

Key words: Business performance, customer satisfaction, e-business, e-business liveability.

\section{Introduction}

E-Business technologies have extended the capability of online wholesalers to collect, target, monitor, profile and even sell individual information about clients to third parties. E-business transactions are conducted via a virtual marketplace where consumers and suppliers meet virtually to exchange information about goods, services and to discuss and implement business transactions [1]. It plays a vital role in the economy, facilitating the exchange of company information, products, payments and service. In the process of e-business operation, e-business firms create economic value for consumers, sellers, society and market intermediaries. There are several e-business organizational variables relevant to its performance measurement i.e.-business strategy, structure, culture, financial issues, e-business infrastructure, e-business liveability, etc. Recent findings in the literature allude that financial performance is a necessary but not sufficient condition for an e-business firm to attain sustainable business growth that represents the imperative of e-business firm's liveability. Liveability of an e-business firm has implications on social, political and economic well-being of local communities as well as for the whole country [2]-[16].

Theoretically explained by [17] balanced scorecard (BSC) framework that embraces four key groups of performance measures of a firm: customer satisfaction; financial performance; internal business processes efficiency and resources utilization effectiveness and organization's learning and growth. They found that traditionally, organizations tend to have a strong focus on financial perspectives. However, they suggested 
that this alone is insufficient to measure the performance of the organization. Rather they should also be supported by other measures such as customer satisfaction, internal processes and the ability to innovate [18]-[30].

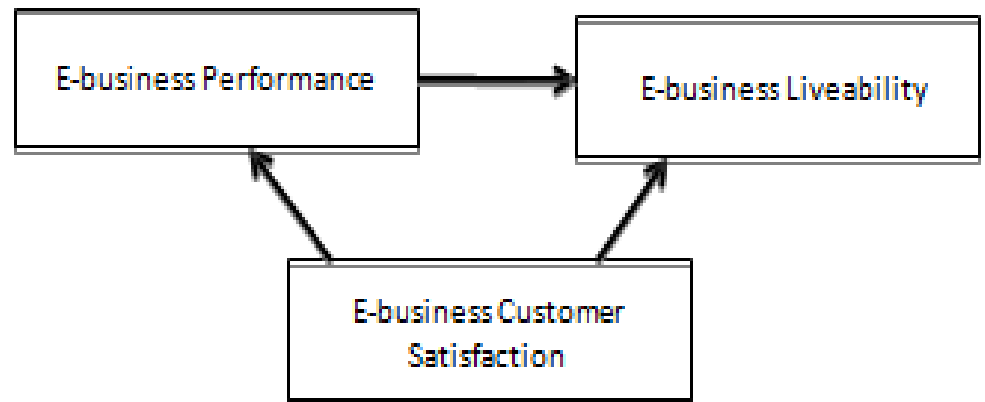

Fig. 1. E-Business customer satisfaction e-business performance and e-business Liveability.

The term, "customer satisfaction" in the context of e-businesses is defined as the degree of satisfaction provided by the services or goods or both of an organization. Customer satisfaction is typically estimated by the number of customers making replicate purchases. It is driven by several organizational variables which include e-business network security, robust and efficient infrastructure, complementary services, reliability and regulatory requirements [2], [13], [16], [18], [24], [28].

Since there is no established framework or definition of liveability, research in this area has focused on empirical studies making comparisons on a wide range of liveability measures such as political, economic social environment; public services; transportation; housing and consumer goods over different geographic locations. However a number of major international liveability studies have been conducted. Some of these are: Mercer Quality of Living Survey; Economist Intelligence Unit (EIU) Quality of Life Index; Demographia International Housing Affordability Survey; Jones Lang LaSalle City Governance Index; Anholt City Brands Index; GaWC World Cities Index and the Monocle Global Quality of Life Survey. Although liveability cannot be objectively measured by quantitative methods, these studies are mainly 'quality of life' and 'cost of life' surveys containing liveability measures as mentioned. For example, under the category of "Culture and Environment" of the EIU Quality of Life rating, the availability of consumer goods and services was used as a liveability measure.

Naturally, the liveability of the e-business implied a high e-business performance. Conversely, may not be true. The mathematical proof of the naturally concept, also known as "axiom" in IT studies, is trivial. Thus, the motivation for this research is to establish empirical evidence on the link between e-business performance and e-business liveability moderated by customer satisfaction. Intuitively, one may argue that there is an indirect link between e-business customer satisfaction and e-business liveability. This research will use a case study from Saudi Arabia as an emerging country with more interesting and less obvious environment than developed or established countries to demonstrate the moderation effect.

\section{Literature Review}

This paper presents a framework of e-business customer satisfaction and e-business liveability. Previous work on the relationship between e-business performance and e-business customer satisfaction have identified five main factors of e-business customer satisfaction, i.e. security, strong infrastructure, complementary requirements, reliability and regularity requirements [5], [15]. This is illustrated in Fig. 2. The following section presents the literature review of e-business customer satisfaction factors.

\subsection{E-Business Customer Satisfaction Factors}

\subsubsection{E-Business security}


The widespread use of Information and Communications Technology (ICT) has increased security threats for e-business company's data. Like any other e-business resource, company data can exist in many forms: film, video, in writing or disc etc. Therefore, Internet security is the process of protecting e-business organizations' resources. In other words, security can be defined as an activity that protects company resources and its infrastructures as well as reducing or eliminating the risks of misuse, loss and damage. It designates controls that an e-business organization needs to implement in order to guarantee that it is rationally managing these risks [13], [27]. Adaptive security, which relates to ensuring sufficient security for ICT infrastructures were found to be directly related to liveability and customer satisfaction.

In the context of e-businesses and liveability there could be many information security threats which includes, 1) Malicious websites: in this threat the hateful URL detections are for web applications that contain exploits; 2) Malicious scripts: Internet hackers inoculate malicious scripts into the program of genuine web application that have had their information security compromised; 3) Scripts and executable threats: these usually refer to the launch and download of other hateful software applications; 4) Trojan: brings numerous malicious applications to customers' computers; 5) Exploits: targets susceptibilities and try to avoid the courtesy of internet security applications etc [10]. In this paper, several security variables are addressed as shown in Fig. 2 in order to identify and explain e-business customer satisfaction.

In the context of e-business, the term e-business network security refers to an activity that protects company resources and its infrastructures as well as reducing the risks of misuse, loss and damage. Strong infrastructure refers to a set of shared resources that work together to attain common e-business goals. A complementary service refers to a service that is offered in addition to an e-business organization necessary service that supports the client in using the service. Reliability is used to identify the ability to attain the required functionality under the particular conditions for a quantified period of time. Regulatory requirements refer to government policies, rules and regulations about e-business.

\subsubsection{Strong infrastructure}

The term E-Business organization infrastructure refers to a set of shared resources that work together to achieve common e-business goals. This includes structures, services, strategies, planning and other installations that are essential for the e-business organization to be successful [19], [21], [22], [24], [26]. E-business infrastructure requires a huge initial investment as it is critical for making correct and accurate decisions to guarantee to the organization receives an adequate return on investment. For instance, buying a new production facility would need a huge initial investment, but it could increase the e- business organization's overall efficiency. Therefore, it would need to regulate that the investment would be covered by the enhancement in productivity before obligating to invest in the organizational infrastructure. Information technology and information systems are areas that frequently require updates as an e-business develops in respect to company performance. This growth not only influences the volume of equipment and software application licenses required, but likewise the application and usage of information technology [20]. Organization infrastructure can be categorized into several variables as presented below.

\subsubsection{Complementary services}

The improvement of service offers in e-business organizations has been termed using different spelling for example "additional services", "complementary services" "product services", and "combined services". The constitutional report distinguishes the services that manufacturing e-business organizations can suggest in various ways such as: company services for company production; services that support e-business organizations in selling activities; a service that is offered by industrialists to assist consumers in selecting, gaining and using the stated company product or supplementary functionalities of this latest strategy; 
externalization of roles that allow e-business organizations to sub-contract high budget specialized services for instance maintenance or informatics [4], [18], [29]. The term complementary is a service that is offered in addition to an e-business organization's essential service that supports the client in using the service. Complementary services in the context of e-service have many applications and can be found in numerous areas. However, in this section we only discussed two dominant application areas of e- services which are as follows: 1) e-business and e-commerce: complementary services typically provided by e-business organizations, non-government or private companies; 2) E-government: complementary services in the domain of e-services provided by government to the public and to public organizations [7], [14]. For the purpose of this paper, several complementary requirements variables have been addressed as shown in Fig. 2 in order to identify the relationship between customer satisfaction and e-business liveability.

\subsubsection{Reliability}

The term 'reliability' can be defined as the ability to attain the required functionality under the specified conditions for a quantified period of time. However, here we only discuss reliability in relation with e-business liveability, where the e-business liveability can be achieved by developing a suitable online web application. Often, the presentation of a web application instigated at a position is rated as good if the computer server at that position is robust and connections are not broken [16], [28]. In this paper, we consider several variables shown in Fig. 2 in order to provide reliable services to the web based applications users in Saudi Arabia.

\subsubsection{Regulatory requirements}

Literature shows that when the Internet came into the kingdom of Saudi Arabia, it carried a new challenge to the government [1]. The government did not want to create a situation where the new technologies interfered with the cultural beliefs of the country and e-business activities in the country have no formal regulations. Reference [9] stated that regulatory problems and company governance have an influence on the e-commerce and e-businesses implementation in Saudi Arabia. Offline payment is the favored payment scheme by some e-services providers since internet users are not enthusiastic to use online payments for safety concerns [9].

Saudi Arabia is a Muslim country and it is obligated to implement Sheria law in all aspects of life, which in turn will influence the adoption of e-businesses in Saudi Arabia. As Sheria law has laid down procedures and regulations for e-businesses, it has unique terminologies which cannot be ignored in a trading environment, for instance, processes for the contract of sale, the meeting place and absentee purchases. According to the Holy book of Quran, trading should not be initiated between two parties in one place and then later completed in a totally different place. In this paper, we consider these variables, i.e. policies, rules and regulations in order to meet the regularity requirements in Saudi Arabia [2], [3]. Further regulatory requirements have been addressed using several sub-variables as shown in Fig. 2.

\subsection{Liveability and e-Business Liveability}

As mentioned, there is no proper definition of liveability, however, liveability literature consists largely of empirical studies, which generally engage a direct assessment of a composite measure over dissimilar geographic areas. There are several studies which grade the liveability of cities or countries. Some are shaped to assess the adversity of particular destinations, while others consider more on the general quality-of-life of a city or country from the viewpoint of existing citizens. Although liveability cannot be measured quantitatively or defined accurately, it is documented as a very significant concept and contemplation in the societies of developed countries. Reference [30] is usually cited for his vision of urban liveability as commonly understood to encompass those elements of home, neighborhood, and urban area 
that donate to safety, economic prospective and welfare, health, expediency, mobility, and leisure.

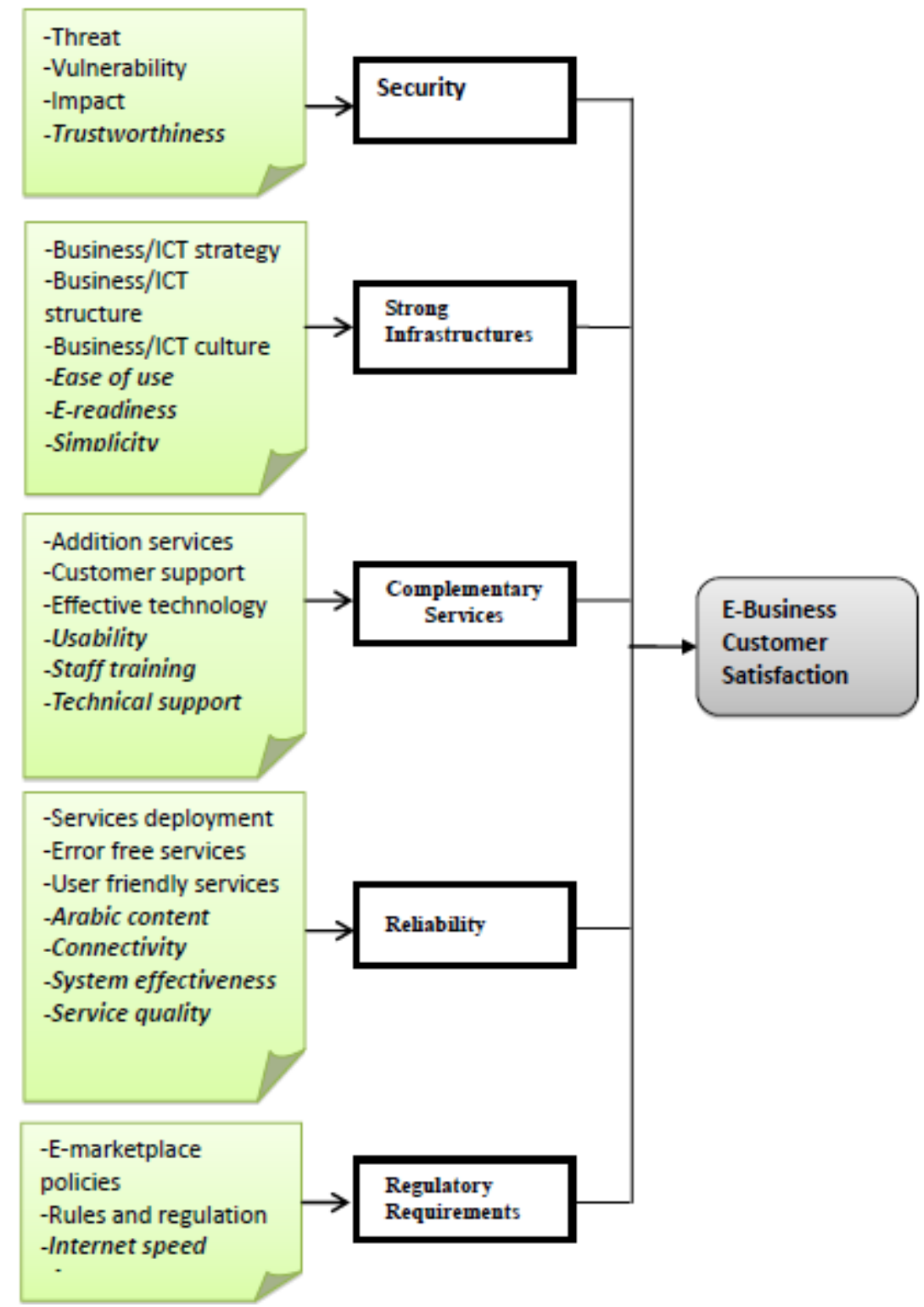

Fig. 2. Driving factors of e-business customer satisfaction strong infrastructure.

Literature shows that business performance management is the area of business intelligence concerned with monitoring and supervision an organization's performance, according to key performance indicators known as KPIs such as income/profit, return on investment, transparency, and operational costs. E-business performance can be measure though various aspect for example business strategy, structure, business infrastructure, culture, revenue, resources, liveability etc. in this paper we defined the term e-business liveability in context of measuring e-business performance. As high e-business liveability leads to high e-business performance and vice versa.

\section{Research Methodology}

When the Internet came into the Kingdom of Saudi Arabia, it brought a new challenge to the Government. The aim of this paper is to identify the e-businesses customer satisfaction relationship with e-business liveability in Saudi Arabia. To validate this research framework interviews have been conducted among 
policy makers from the Saudi Ministry of Commerce and Trade. The interview questions were based on the e-businesses literature [8], [5], [11]. However, some e-businesses variables have been explored during the interview with e-businesses experts and these are discussed in section "result discussion" and later presented in the proposed research framework, which is shown in bold in Fig. 2. The questionnaire was translated into Arabic and revised to better match the e-business liveability and e-businesses contexts. To avoid any bias, the back translation method [12] was used to assure identical or highly similar meaning. The Arabic and English versions were validated and proofread for final approval of the content, wording and clarity of the questions by four experienced academics. A pilot study then was carried out for 7 participants to evaluate the effectiveness of the research instrument. The pilot study suggested some clarifications to the interview instruments [12].

Expert's interviews were categorized into five main variables of e-business liveability in Saudi Arabia, variables which are as follows: e-business security, strong e-business infrastructure, complementary services, e-business reliability and regulatory requirements. The term e-business security refers to activities that relay to the protection of company resources and assets in contradiction to the risks of misuse, loss and damage. In our case variable e-business security further categorized into four subvariables: Threat, Vulnerability, Impact and Trustworthiness. The term e-business organization infrastructure refers to a set of shared resources that work together to achieve common e-business goals. This variable is further categorized into six variables: E-business/ICT strategy, E-business/ICT structure, E-business/ICT culture, Ease of use, E-readiness and Simplicity.

The term complementary is a service that is offered in addition to an e-business organization that supports the client in using the service. This variable is further categorized into six variables: Addition services, Customer support, Effective technology, Usability, Staff training and Technical support. The term reliability in context of an information system is defined as the ability to achieve the required functionality under the specified conditions for a quantified period of time. This variable is further categorized into seven variables: Services deployment, Error free services, User friendly services, Arabic content, Connectivity, System effectiveness and Service quality. The term regulatory requirements represents exponential development of the internet access and online activity and increases the number of new e-business requirements and some other legal questions which are related to copyright and digital content, national laws for cyberspace, privacy and data protection, security of electronic commerce and cyber trade. This variable is also further categorized into four variables: e-businesses policies, Rules and regulations, Internet speed and Awareness.

\section{Data Analysis of Results}

In this section we discuss demographic characteristics, data sample and data analysis.

\subsection{Demographic Characteristics}

Interviews were conducted in order to collect data which would give researchers a better understanding of national cultural differences in relation to the e-business liveability and e-businesses. The study participants were selected only from members of the Saudi Arabia Ministry of Commerce who have experience of dealing in e-businesses and e-services fields in the country. As mentioned the questionnaires were based on e-business literature and were tested on the managers of different successful e-business organizations before discussing them with the participants. The questionnaire was then emailed to the Ministry of Commerce in Saudi Arabia before conducting interviews with experts in the Ministry. The Ministry regulates the means of internal commerce performance, manages the internal markets and protects them against exploitation, breaking of trust and regulation of price control. 
Table 1. Demographic Characteristics of the Participants

\begin{tabular}{|c|c|c|}
\hline Organization Type & Participants & Experts experience \\
\hline $\begin{array}{l}\text { Saudi } \\
\text { Arabia } \\
\text { Ministry of } \\
\text { commerce }\end{array}$ & $\begin{array}{l}\text { - CEO (1) } \\
\text { - Managers (4) } \\
\text { - Engineers (2) }\end{array}$ & More than five years \\
\hline
\end{tabular}

\subsection{E-Business Customer Satisfaction}

Table 2 depicts the questionnaire response rate, where questionnaires comprised several variables that include: security, strong infrastructure, complementary services, reliability and regulatory requirements. All these variables were further categorized into sub-variables as shown in Table 2. The experts were asked to rate each variable on a five point Likert-scale, where 1 meant Not at all important, 2 meant Slightly important, 3 meant Important, 4 meant Very important, and 5 meant Extremely important. After conducting interviews with the experts, the interview data and questionnaires were carefully studied and analyzed. To cross-validate the importance of each selected variable and to answer the previously mentioned research questions, we employed statistical mean to identify the average knowledge level about each variable and it is used to identify the spread of the values of the e-business liveability and e-businesses variables in a particular sample. The purpose of this study is to pursue two main objectives: firstly, the importance of the following e-business customer satisfaction variables: security, strong infrastructure, complementary requirements, reliability and regularity requirements in relation to e-business customer satisfaction and secondly identifying the relationship between e-business customer satisfaction and e-business liveability in Saudi Arabia. Thus, the statistical analysis method is well suited to this study.

For the analysis of our research objective, we divided security, strong infrastructure, complementary services, reliability and regulatory requirements variables into further sub-variables so that each variable could be explored fully, as detailed in Table 2. After independent variable investigation, the average of each sub-variable was calculated and assigned to the parent variable. The data analysis result indicates that e-business variables performance varies from expert to expert, but this variation is very minor. The mean score for the variables security (3.94) which is between Slightly important, and Important, strong infrastructure (3.90) which is between Slightly important, and Important, Complementary services (3.81) which is between Slightly important, and Important, reliability (3.88) which is between Slightly important, and Important and Regulatory requirements (3.94) which is between important, and Very Important.

\subsection{E-Business Liveability}

For the analysis of relationship between customer satisfaction and e-business liveability, we take the mean value of all the variables again and compare with the mean of variable called "e-business liveability". As customer satisfaction has a strong relationship with e-business liveability, if the result of each variable belonging to customer satisfaction is high, the e-business liveability in Saudi Arabia is also high and vice versa. From the expert's interviews, we found that each variable in Fig. 2 and 1.b could positively influence the process of e-business liveability in Saudi Arabia. Fig. 3 presents the result which indicates that customer satisfaction has a strong link with e-business liveability, for example, variables "security", "strong infrastructure", "reliability" and "Regulatory requirements" importance is between Slightly important, and Important which is almost equal to the importance of the variable "e-business liveability".

Moreover, variable "Complementary services" shows importance between important, and Very important which also almost equal to the variable "e-business liveability", according to our third expert in Saudi Arabia as shown in the Fig. 3. 


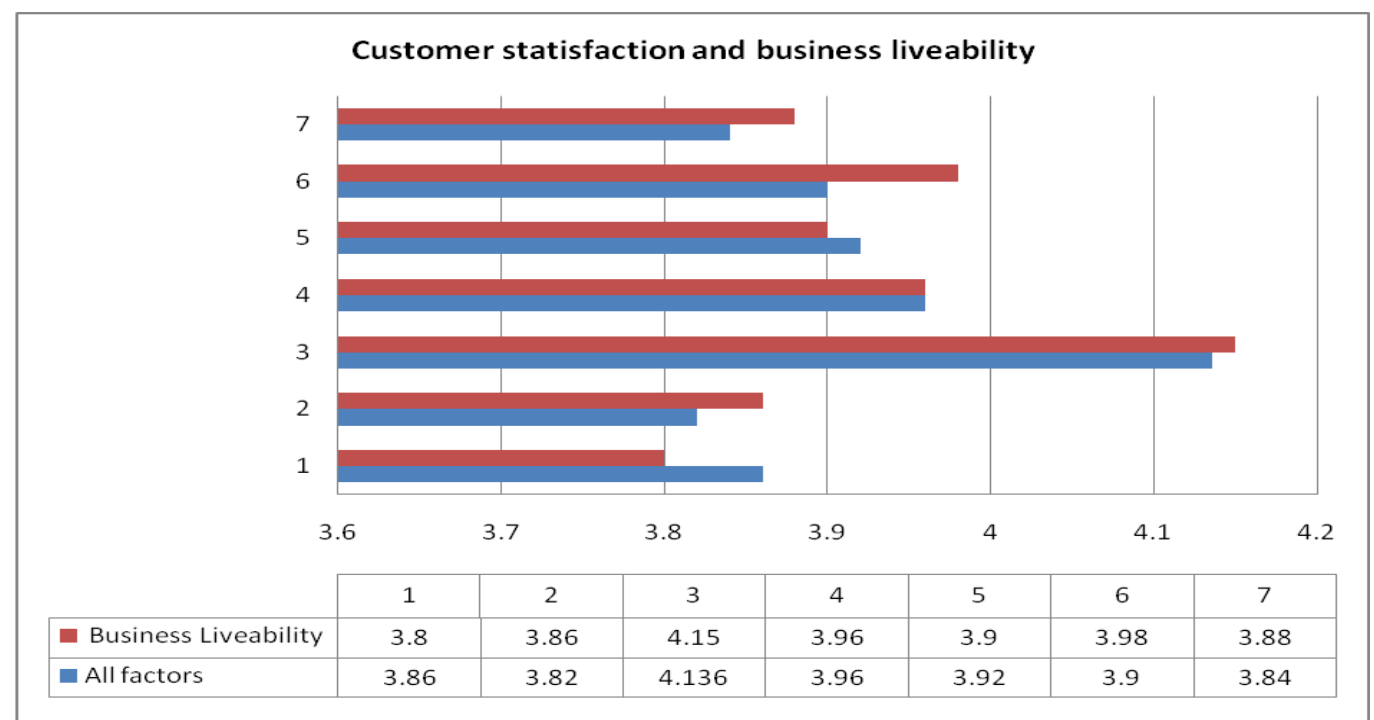

Fig. 3. E-Business customer satisfaction and e-business liveability.

\section{Result Discussion}

This section presents a discussion on our hypothesis results which includes what type of variables are involved in customer satisfaction and answers the question of does e-business customer satisfaction bear as an influence on e-business liveability in Saudi Arabia.

\subsection{Variables Influence on Customer Satisfaction in Saudi Arabia}

A Saudi Arabian recent gazette shows that e-commerce shares in the country hit SR50 billion by 2015 [1]. It is consistently approving new purchasers and refining revenue. Around 1 in 4 Saudi Internet customers are already active in e-commerce, and they visit the site around 70 million times in one month. However, cash on delivery is still the favored method of payment for maximum e-commerce purchasers in the Kingdom. During our interviews with e-commerce experts in Saudi Arabia, our questions were initially based on the e-commerce and e-business liveability literature. However, at the interviews, these experts suggest some other important variables, which are as follows:

\subsubsection{Trustworthiness of organizations}

Out of the seven experts interviewed, six recommended this variable in improving e-commerce customer's satisfaction and e-business liveability in Saudi Arabia. According to them trustworthiness is based on very important variables of trust that have two dimensions: intention and competence. One can ask what is the intention for one to be trustworthy? For one may be interested by self-regard and what they obtain out of being trustworthy. Consider this scenario; someone is selling a used item with mechanical content. He wants a potential purchaser to trust him and his item; the seller may has mentioned that his item is in working order. In this situation, the seller is only concerned with his own interests and not the other party who is considering the purchase of the item. Second, 'Context' is important because the customer need to be comfortable in making a purchase online? For example, the price of an item may be a concern, particularly if the supplier is not well known and many clients do not simply buy laptops according to which one is the ideal, rather which one is the finest deal between the well-known laptops suppliers. Some clients may feel nervous about buying clothing that they cannot touch. One way to overcome this is to review those that were traded for periods through indices. The significant consequence on e-business is to comprehend and convince customers that some products will be more stimulating to trade online than others, like what? The context is conceptually presumed, for example "I belief online 
supplies are sufficiently honest to make purchases", "I belief online supplies are sufficient to make purchases" and "belief online supplies are sufficient to purchase some items, but not sufficient to buying something really significant to the purchaser".

Table 2. Experts Data and Analysis

\begin{tabular}{|c|c|c|c|c|c|c|c|}
\hline \multirow{3}{*}{$\begin{array}{l}\text { E-business } \\
\text { customer } \\
\text { satisfaction } \\
\text { variables }\end{array}$} & \multicolumn{7}{|c|}{ ICT policy makers in Saudi Arabia } \\
\hline & $\underline{\text { Expert } 1}$ & Expert 2 & Expert 3 & Expert 4 & Expert 5 & Expert 6 & $\underline{\text { Expert } 7}$ \\
\hline & Mean & Mean & Mean & Mean & Mean & Mean & Mean \\
\hline Security & 4.0 & 3.7 & 4.3 & 4.0 & 3.7 & 4.2 & 3.7 \\
\hline -Threat & 4 & 4 & 4 & 4 & 5 & 4 & 4 \\
\hline -Vulnerability & 3 & 4 & 4 & 5 & 4 & 5 & 4 \\
\hline -Impact & 4 & 4 & 5 & 4 & 3 & 4 & 3 \\
\hline -Trustworthiness & 5 & 3 & 2 & 3 & 3 & 4 & 4 \\
\hline Strong infrastructure & 3.5 & 4.1 & 4.33 & 4.1 & 3.8 & 3.5 & 4.0 \\
\hline -E-business/ICT strategy & 4 & 4 & 5 & 3 & 5 & 3 & 3 \\
\hline -E-business/ICT & 3 & 4 & 4 & 4 & 4 & 4 & 5 \\
\hline structure & 4 & 5 & 4 & 4 & 3 & 3 & 3 \\
\hline -E-business/ICT culture & 4 & 3 & 3 & 5 & 4 & 4 & 5 \\
\hline -Ease of use & 3 & 4 & 5 & 4 & 4 & 4 & 5 \\
\hline \multirow{2}{*}{$\begin{array}{l}\text {-E-readiness } \\
\text {-Simplicity }\end{array}$} & 3 & 5 & 5 & 5 & 3 & 3 & 3 \\
\hline & 3.8 & 3.5 & 4.0 & 4.0 & 3.8 & 3.6 & 4.0 \\
\hline Complementary services & 3 & 3 & 4 & 4 & 5 & 4 & 5 \\
\hline -Addition services & 4 & 4 & 4 & 4 & 4 & 4 & 4 \\
\hline -Customer support & 4 & 4 & 5 & 5 & 4 & 4 & 4 \\
\hline -Effective technology & 4 & 5 & 3 & 5 & 4 & 5 & 4 \\
\hline -Usability & 5 & 3 & 3 & 4 & 3 & 3 & 5 \\
\hline \multirow{3}{*}{$\begin{array}{l}\text {-Staff training } \\
\text {-Technical support }\end{array}$} & 3 & 2 & 5 & 2 & 3 & 2 & 2 \\
\hline & & & & & & & \\
\hline & 4.0 & 3.8 & 3.8 & 4.0 & 4.1 & 3.7 & 3.8 \\
\hline Reliability & 4 & 3 & 3 & 5 & 4 & 4 & 5 \\
\hline -Services deployment & 3 & 5 & 5 & 3 & 5 & 3 & 5 \\
\hline -Error free services & 4 & 3 & 3 & 5 & 3 & 4 & 3 \\
\hline -User friendly services & 4 & 3 & 4 & 3 & 4 & 3 & 4 \\
\hline -Arabic content & 4 & 4 & 4 & 4 & 5 & 4 & 4 \\
\hline -Connectivity & 4 & 3 & 4 & 3 & 3 & 4 & 2 \\
\hline \multirow{2}{*}{$\begin{array}{l}\text {-System effectiveness } \\
\text {-Service quality }\end{array}$} & 5 & 4 & 4 & 5 & 5 & 4 & 4 \\
\hline & 4.0 & 4.0 & 4.25 & 3.7 & 4.2 & 4.5 & 3.7 \\
\hline Regulatory requirements & 4 & $\mathbf{3}$ & 5 & 4 & 5 & 5 & 5 \\
\hline -E-business policies & 5 & 5 & 5 & 3 & 5 & 4 & 5 \\
\hline -Rules and regulation & 4 & 4 & 3 & 4 & 4 & 5 & 3 \\
\hline -Internet speed & 3 & 4 & 4 & 4 & 3 & 4 & 2 \\
\hline -Awareness & $\mathbf{3 . 8 0}$ & 3.86 & 4.52 & 3.90 & 3.92 & 3.98 & 3.88 \\
\hline
\end{tabular}

Third is 'cooperation'. Trust is connected with cooperation. One may accept that two customers who cooperate must believe each other for a certain period of time. Fourth is 'Uncertainty'. Risk is applicable to all belief. Belief is only a concern if there is some degree of uncertainty involved. One must have sufficient self-reliance in someone to overcome this uncertainty. Fifth, length of relationship, the longer the relationship, the more reliable the parties become. If belief had failed over time, the association would have been superseded in future. Thus, a long relationship between sellers and buyers implies strong belief that extends into an e-business future.

\subsubsection{Ease of use, e-readiness and simple infrastructure}

All experts recommended sub-variables "ease of use", "e-readiness" and "simplicity" in establishing strong infrastructure. According to experts, e-business development can lead to changes to e-business operational necessities and requirements, including the level of organization infrastructure that a company needs to employ in the organization. This change in e-business infrastructure may require a huge initial cost, so it is critical to make correct and accurate decisions to guarantee that the organization receives an 
adequate return on an organization's investment. It could only be possible if e-business infrastructure should be easy to use, e-readiness and simple so that change can be managed.

\subsubsection{Usability, staff training and technical support in complementary services}

Five out of the seven experts recommended usability, staff training and technical support sub-variables in order to support complementary services. According them, services usability refers to the degree to which a service can be employed by specified customers to obtained specified goals and objectives with efficiency, effectiveness and gratification in a quantified context of use. Therefore, staff training is important so that they not only fulfill the customers' requirements, but can also provide technical support to achieve their goals and objectives effectively.

\subsubsection{Arabic content, connectivity, system effectiveness and service quality in the context of reliability}

All experts recommended sub-variables: Arabic content, connectivity, system effectiveness and service quality are all important in the variable called reliability. According to experts some e- businesses in Saudi Arabia are slow in accepting e-commerce and e-business liveability technologies for running their e-business dealings, and that is because of an internal set of organizational variables as well as some external variables of e-business organizations in Saudi Arabia. Therefore, in improving e-business performance in Saudi Arabia it is important that its reliability should be consistent with users' expectations, expose existing faults. Thus, when providing reliable online services to Saudi customers, services should also be: in the Arabic language, always connected, effective and of best quality.

\subsubsection{Internet speed, awareness in regularity requirements}

All experts recommended these sub-variables in order to fulfil regularity requirements in Saudi Arabia. According to them, e-businesses can deliver opportunities to developed e-business processes in the Kingdom. However, adopting a new e-business tool has connected problems and risks as in the case of e-businesses. It is significant to recognize the legal problems and possible risks to guarantee a safe, protected environment for trading with consumers and other e-businesses. These days many e-business organizations in the country are endorsing global synchronization of legal structures, which is based on two main variables:

First, privacy, in typical and online interchange environments, customers are permitted to have their privacy appreciated. E-businesses should deliver the consumers with choices about the use of their individual information, and integrate security procedures to limit use of this by unwanted parties. Therefore, privacy strategies and procedures should be carefully explained to consumers. Although respecting customer privacy privileges is a lawful requirement, it also signifies good e-business practice. For example, if consumers believe in a website and organization is good then they are more likely to do e-business with it. Second, Copyright and Trademark: Many attempts have been prepared to tackle the issues associated to copyright of digital content such as websites and other online material. E-business has a strong impact on copyright and associated issues, and the possibility of copyright is fundamental to how e-businesses evolve. Therefore, it is vital that legal rules are established and applied suitably to guarantee that digital technology does not destabilize the basic principle of copyright and associated rights.

Policies and Laws, at present, are mostly online confidentiality policies that are shaped by private ebusinesses for specific companies. The Saudi Arabia Government is emerging legislation to sustain and strengthen the privacy safety measures of numerous e-businesses. These initiatives are aimed at adapting the storage, employment and expose by e-businesses of individual information. The main issues concerning the legalization of e-businesses include the following: Guarantee appropriate online contracts, record retaining obligations, original documentation, Vat and Tax requirements, improvement regulations, 
interchange control regulation and external data safety law. Therefore, sub- variables "internet speed" and "awareness" are very important in order to improve customer satisfaction and e-business liveability in Saudi Arabia.

\subsection{E-Business Customer Satisfaction Relationship with e-Business Liveability}

In relation to identifying e-business customer satisfaction relationship with e-business liveability, we asked experts to define such customer satisfaction and e-business liveability. All experts agreed that variable e-business liveability at least $20 \%$ to $30 \%$ depends on customer satisfaction in Saudi Arabia. In addition, they raised many other variables: 1) linking e-business strategy with technology strategy: as the organization's formal e-business strategy is hard for technology departments to understand, this may result in the e-business strategy being unclear to the technology department. Likewise, the technology formal strategy is hard for the e-business to understand. 1) Decentralization: e-business organization departments need to be decentralizing to align with the organization's units and the organization's projects. 3) Saudi Culture: a well-managed organizational culture is required in Saudi Arabia in order to develop a working relationship between e-business and technology functions, which leads to improved e-business liveability. 4) Domain Knowledge: some e-business and technology departments in Saudi e-business organizations are not sharing their domain knowledge. By sharing domain knowledge, the communication gap between the two groups is reduced and e-business liveability is high.

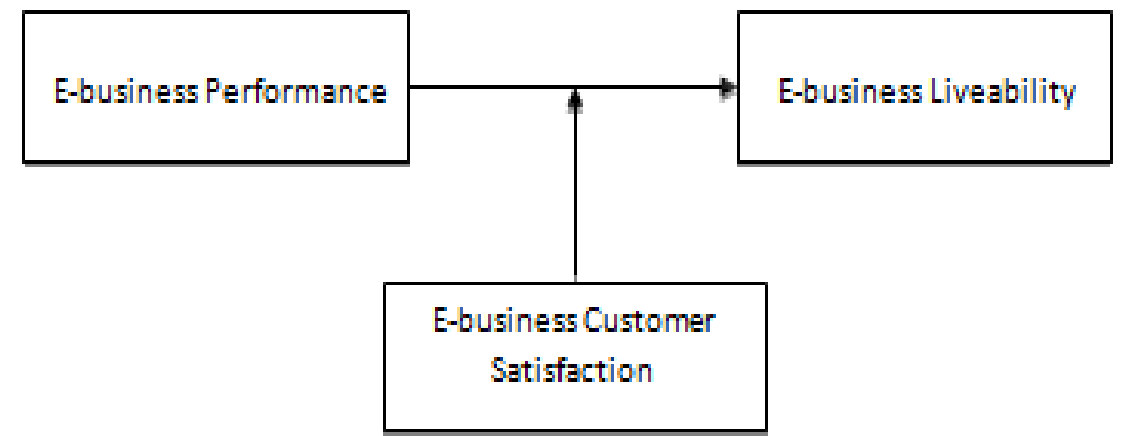

Fig. 4. Compact form of the research model.

Hence based on above findings, the original framework is updated accordingly as shown in Fig. 2. In Fig. 2 variables, which are bold and italic, are explored during the interview with experts. A more compact form of the initial research model as shown in Fig. 1 is given in Fig. 4 below where the e- business customer satisfaction plays a significant moderating role between e-business performance and e-business liveability.

\section{Conclusion and Further Work}

Saudi Arabia is a fast growing and developing country in terms of e-business liveability. Its economy is producing opportunities for both exporters and investors. These are additional advantages boosted by economic improvement, e-business market liberalization, an emergent private sector and moves to expand the economy away from dependence on oil and gas industries. However, in terms of e-business, Saudi Arabia is a country where e-business organizations have a very bright future due to three main reasons. Firstly, it is a country where women are not allowed to drive; thus Saudi women have difficulties going to the shopping malls. Secondly, it is a country where sometimes the temperature goes very high, which makes the environment unsuitable for a healthy life style. Thirdly, it is a country where the government provides many opportunities for new e-businesses thus the fact that it is a tax-free country. Therefore, Saudi customers always prefer to do online shopping and welcome new any e-business offering.

The aim of this paper is to investigate the link between e-business performance and e-business liveability 
using data from Saudi Arabia. It concludes that, if the customers of e-business are satisfied, then the e-business systems are liveable and thus more likely to succeed in the long term. Therefore e-business liveability was found to be a crucial factor of e-businesses in relation their performance. The e-business literature shows several organizational variables that could influence e-business liveability in any country. However, in this paper we have only studied the variable, "customer satisfaction" on e- business liveability applied to Saudi Arabia.

In conclusion, the results of this research suggest: 1) Saudi Arabia is a very good environment for ebusiness platforms; 2) it explored several new e-businesses variables which are important for the success of e-business, particularly in Saudi Arabia; and 3) e-business variable called "customer satisfaction" has a strong relationship with e-business liveability.

Besides customer satisfaction of e-business, there may be other factors that may affect e-business liveability. For instance, other measures of liveability such as business strategy, structure, culture, infrastructure etc. could be used to test the proposed framework. Also, the data used in this research was country-based, findings can investigate against data from other countries or regions in order to further develop the e-business performance and e-business liveability relationship. Thus, future research is vital to address these measures and investigate it world widely so that framework of the relationship the e-business performance and e-business liveability can be validated comprehensively.

\section{References}

[1] Shareef, M. A., Archer, N., \& Dwivedi, Y. K. (2013). Transformational government through EGov: socio-economic, cultural, and technological Issues. Retrieved, 2013, from http://www.saudigazette.com.sa/index.cfm?method=home.regcon\&contentid=20131119187121.

[2] Shehry, A. R., Fairweather, S. N. \& Prior, M. (2006). The motivations for change towards e-government adoption: case studies from Saudi Arabia.

[3] Somali, S. A., Gholami, R., \& Clegg, B. (2009). An investigation into the acceptance of online banking in Saudi Arabia. Technovation, 29(2), 130-141.

[4] Alasem. (2009). An overview of e-government metadata standards and initiatives based on Dublin Core. Electronic Journal of e-Government, 7(1), 1-10.

[5] Algarni, Y. C., \& Lee, V. (2013). An empirical study of eMarketplaces customers' satisfaction: Evidence from Saudi Arabia. Paper presented at the Service Systems and Service Management (ICSSSM).

[6] Ghamdi, R. J. N., \& Drew, S. (2012). Factors Influencing e-commerce Adoption by Retailers in Saudi Arabia: A quantitative analysis. International Journal of Electronic Commerce Studies.

[7] Allen, A., Juillet, L., Paquet, G., \& Roy, J. (2001). E-Governance and government on-line in Canada: Partnerships, people and prospects. Government Information Quarterly, 18(2), 93-104.

[8] Alt, R., \& Klein, S. (2011). Twenty years of electronic markets research-looking backwards towards the future. Electronic Markets, 21(1), 41-51, 2011.

[9] Alwabel, S., \& Zairi, M. (2005). Factors Influencing the Implementation of e-Commerce Technologies by Financial Services in Saudi Arabia: An Empirical Study. University of Bradford, School of Management.

[10] DeMarco, T., \& Lister, T. (2003). Risk management during requirements. Software, 20(5), 99-101.

[11] Eid, M. I. (2011). Determinants of e-commerce customer satisfaction, trust, and loyalty in Saudi Arabia. Journal of Electronic Commerce Research, 12(1), 78-93.

[12] Geal, D. R., Jbarah, S., Meilijson, C., Adelman, \& Levi, H. (2011). The hebrew and the Arabic version of the LittlEARS, Auditory Questionnaire for the assessment of auditory development: Results in normal hearing children and children with cochlear implants. International journal of pediatric otorhinolaryngology, 75, 1327-1332. 
[13] Gilliam, P., \& Feather, M. S. (2004). Security engineering: systems engineering of security through the adaptation and application of risk management. Proceedings of the 14th INCOSE International Symposium and the 4th European Systems Engineering Conference (pp. 20-24).

[14] Janda, S., Trocchia, P. J., \& Gwinner, K. P. (2002). Consumer perceptions of Internet retail service quality. International Journal of Service Industry Management, 13(5), 412-431.

[15] Kuan, H. H., Vathanophas, V., \& Bock, J. W. (2003). The impact of usability on the intention of planned purchases in e-commerce service websites.

[16] Lii, Y. S., Lim, H. J., \& Tseng, L. D. (2004). The effects of web operational factors on marketing performance. Journal of American Academy of Business, 5(2), 486-494.

[17] Kaplan, S. R., \& Norton, D. P. (1992). The balanced scorecard-Measures that drive performance. Harvard Business Review.

[18] Lu, J. (2001). Measuring cost/benefits of e-business applications and customer satisfaction. Proceedings of the 2nd International Web Conference.

[19] Mintzberg, H., Lampel, J. B., Quin, J .B., \& Ghoshal, S. (2003). The strategy process: Concepts, contexts, Pearson Education Limited.

[20] Mumford, W. M. (1979). Computer systems in work design: The ethics method: Effective technical and human implementation of computer system. New York: John Wiley \& Sons.

[21] Pugh, D., Hickson, C., Hinings., \& Turner, C. (1969). The context of organizations. Administrative Science Quarterly, 14(1), 91-114.

[22] Reich, H., \& Benbasat, I. (2000). Factors that influence the social dimension of alignment between business and information technology objectives. MIS Quarterly, 81-113.

[23] Ross, R., Sepper, R., \& Pohjonen, H. (2010). Cross-border teleradiology-experience from two international teleradiology projects. European Journal of Radiology, 73(1), 20-25.

[24] Sapienza, H. J., Smith, K. G., \& Gannon, M. J. (1988). Using subjective evaluations of organizational performance in small business research. American Journal of Small Business, 12(3), 45-53.

[25] Shoniregun, A. (2003). Intellectual property rights of multimedia enriched websites.

[26] [Sullivan, S. S. M. (2003). Economics: Principles in action. Upper saddle river, Pearson Prentice Hall.

[27] Ullah, A., \& Lai, R. (2011). Managing security requirements: Towards better alignment between information systems and business. Pacific Asia Conference on Information Systems.

[28] Wen, R. B. (2000). E-business reliability with web performance management. Proceedings of the IEEE Transactions on Software Engineering(pp. 1122-1146).

[29] Zeithaml, V. A. (2002). Service excellence in electronic channels. Managing Service Quality, 12(3), 135-139.

[30] Vuchic, V. (1999). Transportation for livable cities. Rutgers, Center for Urban Policy Research.

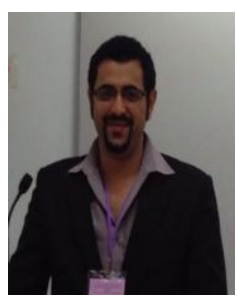

Fahad Algarni is a lecturer in the Department of Computer Sciences at King Khalid University, Abha, Saudi Arabia. He is currently a PhD candidate at Clayton School of Information Technology, Monash University, Melbourne Australia. His PhD research is eMarketplaces' lifecycle issues. He achieved his bachelor degree from the Department of Computer Sciences at King Abdul-Aziz University with First Class Honors. He also graduated with master degree in computer networks from La Trobe University, Melbourne, Australia. His research interests include emarketplaces security, computer networks, systems' reliability, eServices and human-computer interactions. 


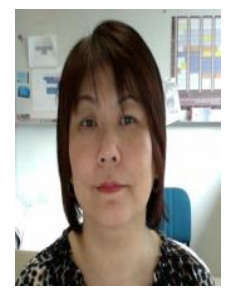

Yen Cheung graduated top of her class with an honours degree in data processing from Loughborough University of Technology (UK) in 1986 and completed her doctorate degree in engineering at the Warwick Manufacturing Group (WMG), University of Warwick in 1991. She worked initially as a teaching fellow and then as a senior teaching fellow at WMG from 1988 - 1994 where she was responsible for the AI and IT courses in the M.Sc. programs in engineering business management. She also ran IT courses for major companies such as British Aerospace, Royal Ordnance, London Electricity and British Airways in UK and for University Technology Malaysia in Malaysia. Besides teaching, she also supervised a large number of industry-based projects. After moving to Australia in 1994, she joined the former School of Business Systems at Monash University. Currently she is a senior lecturer at the Clayton School of IT at Monash University where she developed and delivered subjects in the area of business information systems, systems development, process design, modelling and simulation. Her current research interests are in the areas of collaborative networks such as eMarketplaces particularly for SMEs and development of intelligent algorithms for business systems. She publishes regularly in both international conferences and journals in these areas of research.

Vincent Lee has 25 years of university teaching and research. Vincent Lee worked for private (multinational corporations) and public establishments in Singapore for 13 years during which he involved in engineering system integration and design; the management of operational departments, professionals and projects; led corporate strategic planning and annual corporate budgeting activities. Lee's research interests are multidisciplinary spreading across signal processing; adaptive knowledge representation and information engineering; data, text, and graph mining for knowledge discovery, decision theory. He published 150 articles in peer-reviewed SCI and SSCI international journals and international conference proceedings. He has been awarded 18 internationally competitive research grants in signal processing, decision support systems, and financial engineering research projects

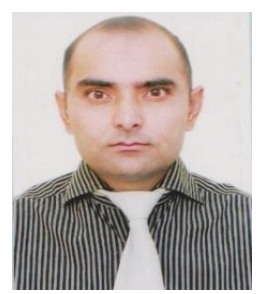

Azmat Ullah is with the La Trobe University, Melbourne Australia. He received the PhD from the Department of Computer Science and Computer Engineering, La Trobe University, Melbourne Australia. he received the MSc degree in advanced software engineering from The University of Sheffield, England, United Kingdom. His current research interests include Business-IT alignment, business process management, business sustainability, green computing, software engineering, software processes, requirements engineering, e-commerce, e-health, and information system development. 